\title{
ANALISIS COST VOLUME PROFIT DALAM MENINGKATKAN PENDAPATAN PADA UKM BALIKPAPAN
}

\author{
Siti Rahmayuni ${ }^{1)}$ dan Risky Masmuddin²) \\ ${ }^{1,2}$ Manajemen, Sekolah Tinggi Ilmu Ekonomi Balikpapan \\ 1,2Jl.Guntur Damai Kalimantan Timur, Balikpapan, 76123 \\ E-mail : sitirahmayuni@stie-balikpapan.ac.id ${ }^{1)}$, riskymasmuddin@stiepan.ac.id ${ }^{2)}$
}

\begin{abstract}
ABSTRAK
Perkembangan akan dunia usaha sungguhlah pesat, seiring perkembangan pesat tersebut persaingan makin meningkat, baik perusahaan yang bergerak pada usaha kecil menengah maupun perusahaan yang go public, Usaha yang harus dilakukan dalam mengatasi hal tersebut adalah membuat perencanaan laba, Perencanaan laba memiliki hubungan yang erat dengan volume penjualan, hasil penjualan, biaya produksi serta biaya operasi perusahaan. Analisis biaya volume laba akan memudahkan perusahaan dalam menentukan target pendapatan dan jumlah biaya yang dikeluarkan dalam upaya mencapai laba yang telah ditentukan tersebut. Tujuan dari penelitian ini adalah Untuk merencanakan laba dengan menggunakan Analisis Biaya-Volume-Laba pada UKM Balikpapan, Untuk mengetahui berapa penjualan yang harus dipertahankan UKM agar tidak mengalami kerugian, metode penelitian ini menggunakn metode pengumpulan data yang didapat melalui observasi dan wawancara serta metode pengolahan data dengan mengumpulkan data mulai dari bahan baku sampai dengan gaji karyawan dan menghitungnya untuk mendapatkan seberapa besar Break Event Poin yang harus didapat, penghitungan Break Even Poin yaitu total revenue dan total cost harus sama, atau dapat juga dihitung dengan rumus Fixed Cost dibagi price dikurangi Variabel Cost, pada pembahasan penelitian didapat beberapa penghitungan Break Event Poin yaitu menghitung titik impas pada jumlah unit, kemudian jumlah rupiah agar para pemilk usaha mengetahui seberapa besar modal yang harus dikeluarkan dan seberapa besar penjualan yang harus dilakukan, adapun hasil penelitian ini adalah Untuk mengembalikan modal usaha maka setiap pengusaha UKM dengan menjual barang produksinya atau barang dagangannya berdasarkan jumlah yang ditentukan dan dapat menargetkan laba yang dinginkan, Dan dengan haasil penelitian ini didapat beberapa UKM yang mengalami peningkatan pada pendaptannya sehingga berpengaruh terhadap laba
\end{abstract}

Kata Kunci: Break Even Point, UKM, Profit, Cost, Volume

\section{PENDAHULUAN}

Perkembangan dunia usaha sangat pesat sehingga setiap usaha dituntut untuk mempunyai target atau tujuan yang akan dicapai setiap periode. Usaha yang harus dilakukan dalam mengatasi hal tersebut adalah membuat perencanaan laba. Dalam melakukan perencanaan, perusahaan sudah menyadari akan segala resiko dan kesulitan yang akan dihadapi dan bisa terjadi sewaktuwaktu. Dalam mengatasi semua masalah tersebut, pihak manajemen harus memiliki kemampuan yang tinggi dalam melihat segala kemungkinan dan kesempatan yang akan datang yang dimulai dari sejak awal untuk mendapatkan tujuan, baik jangka panjang maupun jangka pendek.

Perencanaan laba memiliki hubungan yang erat dengan volume penjualan, hasil penjualan, biaya produksi serta biaya operasi perusahaan. Apabila kondisi perusahaan dan perekonomian mengalami perubahan maka perlu dilakukan analisis dalam merealisasikan laba yang telah direncanakan agar tidak menyimpang dari teknik perencanaan yang digunakan. Teknik perencanaan yang dapat digunakan yaitu dengan analisis cost volume profit. Dimana analisis ini memberikan informasi mengenai besarnya penjualan yang harus dicapai.

Analisis tersebut akan menghasilkan nilai titik impas (break even point, BEP). Analisis cost volume profit akan memudahkan perusahaan dalam menentukan target pendapatan dan jumlah biaya yang dikeluarkan dalam upaya mencapai laba yang telah ditentukan tersebut.

Pentingnya metode dalam penghitungan BEP untuk kemajuan suatu usaha sangat dibutuhkan karena banyaknya UKM di Balikpapan belum melakukan metode tersebut sehingga sering kali pengusaha UKM tidak mengetahui besaran labanya.

Seung (2015) Cost-Volume-Profit Analysis for a Multi-Product Company: Micro Approach dengan hasil penelitian analisis CVP untuk perusahaan multi-produk perlu mengambil langkah ekstra untuk menggambarkan. Untuk kasus perusahaan multi-produk yang memiliki rasio penjualan campuran di antara produk mereka, penelitian ini mengembangkan pendekatan mikro untuk penanganan

desimal, jika muncul, ketika perusahaan menemukan titik impas dan laba target titik. Studi ini mencontohkan bagaimana pendekatan yang dikembangkan mendapatkan jawaban yang lebih dekat dengan titik impas dan target laba dari pada pendekatan yang ada.

Dewi, Ardina, Suardani (2018) Cost-Volume-Profit (CVP) Analysis as a Profit Planning of Tour Packages at PT Tour East Indonesia, Denpasar denga hasil menunjukkan bahwa analisis biaya-volume-laba (CVP) dapat membantu manajemen dalam perencanaan laba 
dan juga memberikan informasi tentang nilai jual impas dari paket wisata untuk 2018 sebesar Rp. 5.915.226.769 atau 1.352 pax atau $27 \%$ dari penjualan dianggarkan pada tahun 2018. Jika perusahaan ingin mencapai target laba $20 \%$ dari laba tahun 2017, maka volume penjualan paket wisata yang harus dicapai adalah Rp. 27.753.815.507. Tingkat keamanan penjualan perusahaan menurun sehingga tidak menderita kerugian pada 2018 sebesar $73 \%$.

Enkeleda, Etem Iseni (2018) Role of Analysis CVP (Cost-Volume-Profit) as Important Indicator for Planning and Making Decisions in the Business Environment penelitian menunjukkan bahwa jumlah produk yang dihasilkan berpengaruh positif terhadap nilai penjualan ke perusahaan jasa dan meningkatkan laba ke lingkungan bisnis manufaktur, juga ada hubungan penting antara produksi dan penjualan, dan analisis CVP berkontribusi terhadap pertumbuhan profitabilitas dan impas dalam bisnis lingkungan Hidup . Jadi, sebagai kesimpulan berdasarkan hasil yang ditemukan dari penelitian, analisis biaya-volume-laba harus digunakan untuk membuat keputusan, karena ambang risiko jelas menurun dengan melakukan analisis tersebut. Besar permintaan dari perusahaan jasa untuk produk yang secara signifikan meningkatkan laba dan memproduksi hingga manufaktur Perusahaan

JIhemeje, Geff, Bashir, Ogungbangbe (2015) CostVolume-Profit Analysis And Decision Making In The Manufacturing Industries Of Nigeria dengan Hasil penelitian mengungkapkan bahwa nilai penjualan suatu produk dan jumlah produk yang diproduksi memiliki efek positif terhadap laba yang dihasilkan pada produk tersebut, juga bahwa ada hubungan yang signifikan antara biaya produksi dan laba. Urutan ulang dan kuantitas pesanan ekonomi juga ditentukan sebagai dasar untuk menilai peluang pengambilan keputusan. Berdasarkan hasil, peneliti merekomendasikan bahwa industri manufaktur harus selalu mengadopsi analisis laba volume biaya dalam pengambilan keputusan mereka.

Vedat Ekergil (2017) Use of Cost-Volume-Profit Analysis Technique in Customer Profitability Analysis and Model Suggestion for Businesses dengan hasil penelitian bahwa total keuntungan dari pelanggan yang menguntungkan sangat banyak, total laba yang terkait dengan produk. Telah ditentukan bahwa penyebab Perbedaannya adalah karena hilangnya pelanggan yang tidak menguntungkan. Dengan melakukan berbasis pelanggan analisis biaya-volume-laba; peningkatan berkelanjutan dalam kebijakan penjualan dan diskon untuk

dibuat agar pelanggan bisa tercapai. Selain itu, manajemen manajer bisa direalisasikan dengan bantuan model ini dengan menyelamatkan manajemen dari manajemen dari pelanggan.

\section{RUANG LINGKUP}

1. Cakupan permasalahan.

1) Berapa besar titik impas (BEP) yang di dapat pada produksi UKM

2) Berapa jumlah produksi yang harus dicapai untuk mendapatkan laba

2. Batasan-batasan penelitian.

Penelitian ini di batasi dengan penghitungan BEP dan laba yang dicapai UKM

3. Rencana hasil yang didapatkan

Memberi penjelasan kepada UKM cara menghitung BEP dan Laba untuk setiap produk yang dihasilkan

\section{BAHAN DAN METODE}

Metode yang dipakai dalam penulisan adalah metode analisis deskriptif kuantitatif, ialah menjelaskan hasil penelitian yang berupa data transaksi yang berhubungan dengan biaya. Data berupa kumpulan biaya-biaya dan pendapatan UKM untuk menghitung jumlah BEP yang didapat

Sugiyono (2015) pengertian deskriptif adalah Penelitian deskriptif adalah penelitian yang dilakukan untuk mengetahui keberadaan variabel mandiri, baik hanya pada satu variabel atau lebih tanpa membuat perbandingan atau menghubungkan dengan variabel lainnya

\subsection{Pengertian Biaya}

Mulyadi (2015) "Biaya adalah pengorbanan sumber ekonomis yang diukur dalam satuan uang, yang telah terjadi, sedang terjadi atau yang kemungkinan akan terjadi untuk tujuan tertentu."

Abdullah (2012) yaitu "Biaya adalah pengeluaranpengeluaran atau nilai pengorbanan untuk memperoleh barang atau jasa yang berguna untuk masa yang akan datang, atau mempunyai manfaat melebihi satu periode akuntansi".

Siregar dkk (2014) yaitu "Cost adalah pengorbanan sumber ekonomi untuk memperoleh barang atau jasa yang diharapkan memberikan manfaat sekarang atau masa yang akan datang.

\subsection{Analisis CVP ( Cost - Volume- Profit)}

Blocher, dkk, (2011) Analisis biaya-volume-laba (cost-volume-profit- CVP Analysis) merupakan suatu metode untuk menganalisis bagaimana pengaruh keputusan operasi dan pemasaran terhadap laba berdasarkan pemahaman atas hubungan antara biaya variabel, biaya tetap, harga jual per unit, dan tingkat output

Analisis Cost - Volume - Profit adalah kunci untuk memahami perilaku biaya. Manajer menggunakan analisis biaya-volume-laba untuk mendorong keputusan mereka dan semuanya strategis. Orang harus ingat bahwa pelanggan adalah dasar untuk operasi bisnis. Antara pelanggan menuntut kebutuhan dan menarik barang dari 
perusahaan atau perusahaan temukan kebutuhan dan dorong barang ke pelanggan.

Perusahaan mengukur profitabilitas produk dengan menghitung biaya barang yang dijual saat menentukan total profitabilitas. Ini mengarahkan perusahaan untuk mengevaluasi yang menguntungkan dan tidak menguntungkan pelanggan bersama. Investasi yang dilakukan untuk pelanggan nirlaba, mengurangi profitabilitas dan efisiensi perusahaan dengan meningkatkan biaya. Ini Intinya, menjadi lebih penting untuk mengukur profitabilitas pelanggan. Ini adalah titik awal untuk mengidentifikasi pertanyaan penelitian untuk penelitian ini. Dalam studi ini, pertama, analisis biayavolume-laba-laba berbasis-produk dan kemudian-labalaba berbasis-pelanggan analisis diperiksa

\subsection{Perencanaan Laba}

Mulyadi (2015) Perencanaan laba yang baik dan cermat tidak mudah karena teknologi berkembang dengan cepat dan faktor sosial, ekonomi pilitik berpengaruh kuat dalam dunia usaha. Perencanaan laba menurut Mulyadi adalah proses pembuatan rencana kerja untuk jangka waktu satu tahun, yang dinyatakan dalam satuan moneter dan satuan kuantitatif yang lain.

\subsection{Manfaat Perencanaan Laba}

Menurut Garrison (2008) analisis perencanaan laba dapat digunakan untuk menentukan volume penjualan yang dibutuhkan untuk mencapai target laba. Menurut Horngren, et al (2008:80) analisis sensitivitas adalah teknik "bagaiman jika (what-if) yang digunakan manajer untuk menguji bagaimana akibatnya jika prediksi data awal tidak tercapai atau jika asumsi yang mendasarinya berubah.

\subsection{Analisis Break Even Point (Titik Impas)}

Menurut Hansen dan Mowen (2005), analisis impas merupakan "suatu cara untuk mengetahui volume penjualan minimum agar suatu usaha tidak mengalami kerugian, tetapi juga belum memperoleh laba." Dengan adanya analisis impas ini, perusahaan dapat mudah melakukan pengawasan volume penjualan dalam mencapai target laba yang ditentukan.

\section{PEMBAHASAN}

Analisis titik impas merupakan suatu alat yang sering digunakan oleh manajemen di dalam pengambilan keputusan atas masalah yang berkaitan dengan harga, biaya, volume produksi dan penjualan serta keuntunga. untuk mengetahui pada volume (jumlah) penjualan dan volume produksi berapakah suatu perusahaan yang bersangkutan tidak menderita kerugian dan tidak pula memperoleh laba. Berikut disajikan tabel data penjualan beberapa UKM.

\subsection{Usaha Keripik Singkong Pedas}

Tabel 1. Total Cost Keripik Singkong Pedas

\begin{tabular}{|r|l|r|}
\hline No & Keterangan & Harga \\
\hline 1 & Singkong & 250000 \\
\hline 2 & Gula Merah & 60000 \\
\hline 3 & Cabai Rawit & 60000 \\
\hline 4 & Cabai Merah & 120000 \\
\hline 5 & Bawang Merah & 38000 \\
\hline 6 & Bawang Putih & 50000 \\
\hline 7 & Garam & 5000 \\
\hline 8 & Minyak Goreng & 75000 \\
\hline 9 & Gas 3 Kg & 20000 \\
\hline 10 & Air Galon & 12000 \\
\hline 11 & Plastik Es & 10000 \\
\hline & Total & 700000 \\
\hline
\end{tabular}

BEP

$\begin{array}{rll}\mathrm{TR} & = & \mathrm{TC} \\ 4.000 \times \mathrm{Q} & = & 700.000 \\ \mathrm{Q} & = & \frac{700.000}{4.000} \\ \mathrm{Q} & = & 175 \\ \text { BEP Rupiah } & = & 4.000 \times 175 \\ & = & 700.000\end{array}$

Bila menginginkan laba sebesar $25 \%$ maka besarnya penjualan adalah;

$4.000 \times 175+25 \%=875.000$ sehingga harus menjual sebanyak 218,75 pcs

\subsection{Usaha Minuman Dot}

Tabel 2. Total Cost Minuman Dot

\begin{tabular}{|r|l|r|}
\hline No & Keterangan & \multicolumn{1}{|l|}{ Harga } \\
\hline 1 & Botol Dot & 9900000 \\
\hline 2 & Susu & 2400000 \\
\hline 3 & Gula & 252000 \\
\hline 4 & Bubuk & 2475000 \\
\hline 5 & Air Galon & 165000 \\
\hline 6 & Biaya Lain lain & 4100000 \\
\hline & Total & 19292000 \\
\hline
\end{tabular}

\begin{tabular}{|c|c|c|}
\hline BEP & & \\
\hline TR & $=$ & $\mathrm{TC}$ \\
\hline $25000 \times \mathrm{Q}$ & $=$ & 19292000 \\
\hline $\mathrm{Q}$ & $=$ & 19292000 \\
\hline & & 25.000 \\
\hline $\mathrm{Q}$ & $=$ & 771,68 \\
\hline BEP Rupiah & $=$ & $25.000 \times 771,68$ \\
\hline & $=$ & 19.292 .000 \\
\hline
\end{tabular}


Perencanaan Laba Bila menginginkan laba sebesar 25 $\%$ maka besarnya penjualan adalah:

$25.000 \times 771.68+25 \%=24.115 .000$ sehingga harus menjual sebanyak 964,65 pcs

\subsection{Usaha Keripik Kentang Pedas}

Tabel 3 Total Cost Keripik Kentang Pedas

\begin{tabular}{|c|l|r|}
\hline No & Keterangan & Harga \\
\hline 1 & Kentang & 1375000 \\
\hline 2 & Gula Merah & 300000 \\
\hline 3 & Cabai Merah & 340000 \\
\hline 4 & Cabai Rawit & 312000 \\
\hline 5 & Kacang Tanah & 187000 \\
\hline 6 & Bawang Merah & 225000 \\
\hline 7 & Bawang Putih & 237500 \\
\hline 8 & Garam & 7000 \\
\hline 9 & Minyak Goreng & 750000 \\
\hline 10 & Gas 3 kg & 264000 \\
\hline 11 & Air Galon & 12000 \\
\hline 12 & Toples & 1250000 \\
\hline 13 & Sticker & 200000 \\
\hline 14 & Isolasi & 50000 \\
\hline 15 & Transport & 300000 \\
\hline 16 & Tas Kresek & 20000 \\
\hline 17 & Pegawai & 1000000 \\
\hline & Total & 6829500 \\
\hline
\end{tabular}

\section{BEP}

TR

$\begin{array}{rll}25000 \times \mathrm{Q} & = & 6829500 \\ \mathrm{Q} & = & \underline{6829500} \\ \mathrm{Q} & = & 25.000 \\ \mathrm{TR} & & 273,18\end{array}$

BEP Rupiah $\quad=\quad 25.000 \times 273,18$

$$
=6829500
$$

Bila menginginkan laba sebesar $25 \%$ maka besarnya penjualan adalah:

$25.000 \times 273,18+25 \%=8.536 .875$ sehingga harus menjual sebanyak 341.475 pcs

\subsection{Usaha Salome}

\section{Tabel 4 .Total Cost Salome}

\begin{tabular}{|r|l|r|}
\hline No & Keterangan & Harga \\
\hline 1 & Ayam & 55000 \\
\hline 2 & Daging & 40000 \\
\hline 3 & Jasa Giling & 59000 \\
\hline 4 & Tahu & 10000 \\
\hline 5 & Cabai & 22000 \\
\hline 6 & Gula $1 \mathrm{Kg}$ & 14000 \\
\hline 7 & Kacang Tanah $1 \mathrm{Kg}$ & 25000 \\
\hline
\end{tabular}

\begin{tabular}{|c|l|r|}
\hline 8 & Tepung kanji & 5000 \\
\hline 9 & Gas $3 \mathrm{Kg}$ & 22000 \\
\hline 10 & Plastik Es & 7000 \\
\hline 11 & Bawang Putih & 20000 \\
\hline 12 & Kecap Manis & 13000 \\
\hline 13 & Saos Tomat & 10000 \\
\hline 14 & Kenderaan & 6000000 \\
\hline 15 & Rombong & 2000000 \\
\hline 16 & Gaji Pegawai & 800000 \\
\hline & Total & 9.122 .000 \\
\hline
\end{tabular}

BEP

$\begin{array}{lll}\mathrm{TR} & = & \mathrm{TC} \\ 5000 \times \mathrm{Q} & = & 9.122 .000 \\ \mathrm{Q} & = & \underline{9.122 .000} \\ & & 5.000 \\ \mathrm{Q} & = & 1.824,4 \\ \text { BEP Rupiah } & = & 5000 \times 1824,4 \\ & = & 9.122 .000\end{array}$

Bila menginginkan laba sebesar $25 \%$ maka besarnya penjualan adalah:

$5.000 \times 1824,4+25 \%=11.402 .500$ sehingga harus menjual sebanyak $2.280,5 \mathrm{pcs}$

4.6 Usaha Keripik Tempe

Tabel 5 Total Cost Keripik Tempe

\begin{tabular}{|r|l|r|}
\hline No & Keterangan & Harga \\
\hline 1 & Tempe & 600000 \\
\hline 2 & Minyak Goreng & 125000 \\
\hline 3 & Tepung Tapioka & 80000 \\
\hline 4 & Garam & 1000 \\
\hline 5 & Plastik Es & 12000 \\
\hline 6 & Biaya Lain-lain & 100000 \\
\hline 7 & Gaji Karyawan & 800000 \\
\hline & Total & 998000 \\
\hline
\end{tabular}

BEP

$\begin{array}{lll}\mathrm{TR} & = & \mathrm{TC} \\ 12500 \times \mathrm{Q} & = & 998.000 \\ \mathrm{Q} & = & \frac{998.000}{12.500} \\ \mathrm{Q} & = & 79,84 \\ \text { BEP Rupiah } & = & 12.500 \times 79,84 \\ & = & 998.000\end{array}$

Bila menginginkan laba sebesar $25 \%$ maka besarnya penjualan adalah:

$12.500 \times 79,84+25 \%=1.247 .500$ sehingga harus menjual sebanyak 99.8 pcs 


\section{KESIMPULAN}

Untuk mengembalikan modal usaha maka setiap pengusaha UKM menjual barang produksinya atau barang dagangannya berdasarkan jumlah yang ditentukan dan dapat menargetkan laba yang dinginkan.

Usaha keripik singkong pedas menggunakan biaya sebesar Rp 700.000 dengan harga jual sebesar Rp 4.000 sehingga untuk berada pada titik impas pihak pengusaha harus menjual sebanyak $175 \mathrm{pcs}$

Usaha minuman DOT menggunakan biaya sebesar Rp 19.292.000 dengan harga jual sebesar Rp 25.000 sehingga untuk berada pada titik impas pihak pengusaha harus menjual sebanyak 771,68 pcs

Usaha Keripik Kentang Pedas menggunakan biaya sebesar Rp 6.829.500 dengan harga jual sebesar Rp 25.000 sehingga untuk berada pada titik impas pihak pengusaha harus menjual sebanyak 273,18 pcs

Usaha Salome menggunakan biaya salome sebesar Rp 9.122.000 dengan harga jual sebesar Rp 5000 sehingga untuk berada pada titik impas pihak pengusaha harus menjual sebanyak $1.824,4$ pcs

Keripik Tempe menggunakan biaya sebesar Rp 998.000 dengan harga jual sebesar Rp 12.500 sehingga untuk berada pada titik impas pihak pengusaha harus menjual sebanyak 79,84 pcs

Keripik Tempe biaya yang digunakan sebanyak Rp 918.000 dengan harga jual Rp 12000 dan untuk BEP nya pengusaha harus menjual sebanyak 76,5 bungkus keripik

\section{SARAN}

Setiap UKM sebaiknyaa menggunakan analisis Volume Cost dan Profit untuk menentukan BEP, dan pencapaian tujuan untuk besaran laba harus mengetahui jumlah produksi dengan harga jual produknya

Dalam melakukan transaksi sebaiknya setiap UKM dapat membuat laporan keuangan sehingga mempermudah UKM dalam menghitung laba penjualan.

\section{DAFTAR PUSTAKA}

Blocher., Edward J. Stout., David E dan Cokins., Gary, 2011. Manajemen Biaya. Edisi Kelima. Buku Satu. Salemba Empat. Jakarta

Carter, William.K, dan Milton F. Usry, 2016. Akuntansi Manajemen. PT. Rajagravindo Persada. Jakarta

Dewi, Ardina, Suardani, .2018. Cost-Volume-Profit (CVP) Analysis as a Profit Planning of Tour Packages at PT Tour East Indonesia, Denpasar. Journal of Applied Sciences in Accounting, Finance, and Tax, [S.1.], v. 1, n. 1, p. $7-13$

Enkeleda .2018. Role of Analysis CVP (Cost-VolumeProfit) as Important Indicator for Planning and Making Decisions in the Business Environment European Journal of Economics and Business Studies p 104

Ekergil .2017. cost-volume-profit analysis on the basis of the product mix generated by each customer's Journal of Business Research-Türk. P 488

Hongren, Charles T., Datar, Srikant M., dan Foster, 2018. Akuntansi Biaya Penekanan Manajerial, Jilid 1. Edisi Kesebelas. Indeks. Jakarta

Ihemeje .2015. Cost-volume-profit Analysis and Decision Making in the Manufacturing Industries of Nigeria Journal of International Business Research and Marketing p 7-15

Kasmir. 2010. Aanalisis Laporan Keuangan.ed.2. Yogyakarta: BPFE Group

Mulyadi, 2010. Akuntansi Biaya. Edisi Empat. BPFE. Yogyakarta

Seung 2015. Cost-Volume-Profit Analysis for a MultiProduct Company: Micro Approach International Journal of Accounting and Financial p23

Sugiyono. 2008. Metodologi penelitian Kuantitatif, Kualitatif, dan R\& D. Bandung: Alfabeta. 